\title{
The Cambridge handbook of copyright limitations and exceptions.
}

\author{
OPPENHEIM, C.
}

2021

This is a pre-copyedited, author-produced version of an article accepted for publication in European Intellectual Property Review following peer review. The definitive published version OPPENHEIM, C. 2021. The Cambridge handbook of copyright limitations and exceptions. European intellectual property review [online], 43(7), pages 479-481, is available online on Westlaw UK. 
The Cambridge Handbook of Copyright Limitations and Exceptions

Edited by S. Balganesh, N.W. Loon and H. Sun

Cambridge University Press, 2021

ISBN 978-1-108-48304-9

$£ 160$ hardback

This 419-page heavyweight tome comprises 22 chapters contributed by experts, many of them very well known, together with an anonymous brief Preface. The chapters are organised into five parts, which reflect the broad themes covered. The text makes you want to read it cover to cover, rather than what we more commonly do with handbooks, which is to home in on chapters of interest.

The topics covered in this collection of essays cover theoretical foundations of exceptions, international aspects, models on exceptions, workings of exceptions, and a final chapter on technology. Despite the book's title, this not really a Handbook if one uses that term to mean a reference work providing instructions; why not just remove the first four words of the title? The chapters vary in length from about 10 pages to about 30 pages.

Chapter 3, by Aplin and Bently, is, in essence, a primer on their important new book Global Mandatory Fair Use. Several authors note that the concept of "users' rights" is not generally accepted, and argue that it really should be.

As Hilty and Moscon in Chapter 4 describe the interesting project to develop an international instrument for permitted uses of copyright works (an instrument that has recently been published in full, but is described in broad terms in the chapter). They noted that "it is no secret that European (and generally Western) policy mostly considers the interests of the copyright industry as a priority." This is exemplified in the UK by a recent statement of 
the Minister of Higher Education (Michelle Donelan), when responding to complaints about the high price of e-textbooks in the UK, ignored the complaint but instead thanked the UK Government for supporting the academic publishing industry.

Martin Senftleben's excellent Chapter 5 has the intriguing title "Nightmare or a Dream Come True?" to explore the Marrakesh Treaty. He concludes that bearing in mind the tensions involved, it is a miracle the Treaty was adopted, but he claims there is a real risk that Treaty offers neither legal certainty or sufficient flexibility.

Unsurprisingly, a recurring theme in the chapters is the tension between the flexibility but uncertainty of fair use exceptions, versus the certainty, but rigidity of fair dealing lists of exceptions. This is explored in detail in the excellent Chapter 7, "Debunking the Fair Use vs Fair Dealing Myth" by Ariel Katz. This chapter focusses on Canada as an example. Katz noted in passing that why the UK chose the term "dealing" rather than "use" remains a mystery; indeed, it is something that has long puzzled me. The author argues that Parliament sought to codify a principle - a flexible standard, not precise rules, and the result is confusion.

Other authors, however, argue that the differences in approach between fair dealing and fair use are less significant than might appear on the surface. Handler and Hudson in Chapter 8 examine fair use vs fair dealing in Australia in their carefully argued chapter. They argue that expansions to fair dealing in Australia might be as good as the adoption of a fair use system, as the latter, although desirable is politically controversial.

In Chapter 9, Robert Burrell looks at UK judicial interpretations of exceptions to copyright, and concludes that judges in copyright cases are not only weighing the interests of copyright owners against users, but have a more 
fundamental role in holding the executive to account by setting limits to the ability of national governments to make the rules when international legal obligations are in place.

Some of the chapters refer to local situations; for example, Kung-Chung Liu in Chapter 11 compares Taiwan's approach to exceptions ton those of China. I was surprised to learn that there is an agreement on Intellectual Property Rights Protection and Co-operation between the two countries, despite the fact that officially China does not recognize Taiwan as a separate country. Similarly, the very brief Chapter 12 , by Tatsuhiro Ueno, examines Japan's fair use exception, whilst Ida Azmi in Chapter 13 provides a useful examination of Malaysia's attempt to bridge fair dealing and fair use.

In a lengthy essay, Chapter 14 by Haochen Sun looks at the need to establish public interest principles for the adjudication of cases involving exceptions, whilst Daniel Seng in Chapter 15 looks at education as the basis of exceptions to copyright. His chapter includes some original research - an analysis of the number of provisions for exceptions to copyright relevant to education to be found in each WIPO Member State's laws. The most common examples were private/personal use and quotation for educational purposes. The "best performing" country is Australia, with 32 such limitations relevant to education, though of course such numbers are pretty meaningless without any explanation of whether these limitations in legislation are in practice used or useful- something the author does not address.

Chapter 26 by Arpan Banerjee, looks at a specific case (the Delhi University Photocopying case), with detailed historical background and an interesting account of the twists and turns of this case as it went through the courts. In the end, the publishers 'tactics seem to have backfired.

The next two chapters look at the Satire/Parody exceptions around the world, 
with interesting discussions on the differences between the two terms. It is noted that these exceptions "tend to bruise a few egos more than make a hole in the pockets of rights owners." A footnote records that a judge in a case of a Barbie parody that had involved the parties publicly throwing invectives at each other, stated "the parties are advised to chill". It is a pity that the two chapters on parody do not cross-refer to each other. The second parody chapter by Christoph Rademacher is rather spoiled by the fact that the Figure numbering in the text does not always correspond to the actual Figures in the Chapter. Whether this is the fault of the original author, the publisher, or the editors is unclear, but it certainly spoils what is otherwise an interesting chapter. Rademcher concludes that how the parody exception is used depends very much on the culture of the country concerned.

Chapter 19, on Hong Kong's approach to Fair Dealing by Alice Lee and Brendan Clift, is unfortunately timed, as some of its remarks about the Hong Kong legal system have been overtaken by decisions taken by the Peoples Republic of China.

Chapter 20 by Graeme Austin looks at the news reporting exception, drawing attention to an interesting case, Heythrop Zoological Gardens vs Captive Animals Protection Society, but footnote 35 makes an incorrect statement "Copyright, Designs and Patents Act 1988, s 180 (2) [hereinafter CAPS]"; this merges what should have been two separate footnotes into one. Again, it is unclear whose fault this error is.

Chapter 21 by Wee Loon (one of the editors of the book) on copyright and religion examines the differences in exemptions for the playing of religious music and singing religious songs between Malaysia, Singapore and UK. It notes in passing the Philip and Mary used the Stationers Company monopoly (later transformed into the 1709 Copyright Act) to suppress the spread of detestable heresies against the faith and doctrine of the Holy Mother Church, i.e., the Catholic Church. The argument is that the 1709 Act was a way of 
permitting alternative religious viewpoints. This chapter explores the role of music and songs in Buddhism/Taoism, Christianity, Hinduism and Islam, and the impact of this on exceptions in Malaysia and Singapore. Whilst both laws are based on the UK Copyright Act 1911, Singapore allows an exception for the use of music in worship, whereas this is not the case in Malaysia. The author suggests that this reflects both the dominant religions of each country and their use of music in their respective cultures. The author of this interesting chapter concludes that in the UK, although authors of religious music songs compose for the glory of God, this does not mean these authors should find their reward only in Heaven!

Chapter 22, the final one, represents musings David Nimmer first put down five years ago regarding what the future impact on rights holders of the use of exceptions might be in years to come. Although the Section is entitled "Copyright Exceptions and Technology", the chapter, though interesting, is really only focused on how to estimate future potential losses, and is not directly to do with the impact of technology on copyright exceptions.

It is a pity there weren't more contributions on what technological and social developments might have on exceptions. Fan fiction gets mentioned by some authors; it is a pity this wasn't explored in more depth in the book.

As might be expected from such an eminent list of authors and interesting range of topics, the contributions are well written, interesting, well supported with references and authoritative.

Unfortunately, most of the chapters seem to have been written without the author being able to see the chapters from the other authors, and there is therefore almost no cross-referencing between the chapters, even when they cover the same themes, or cite the same court cases. The latter is particularly frustrating for the reader because - and this is the key weakness 
of this book - there is no subject index, index of cases, or index of legislation provided in the book. Thus, one would like to see how different authors have interpreted, say, the WIPO Marrakesh Treaty, The Gowers Review, Article 10(1) of Berne, or Campbell v Acuff-Rose, but the reader cannot. I find it astonishing that such an important collection of essays has been spoiled because the publishers were not prepared to spend some money on such indexes.

Other more minor criticisms of the book include the occasional typo (for example "intended" should be used, not "indented" on page 121), the fact that despite the recency of this publication, there is no mention of public interest tests relating to using exceptions in a medical emergency, that some references given in footnotes by the chapter authors are incomplete, and there is not complete consistency in the way references are cited between the various chapters. This would not be a problem if a full bibliography for each chapter were provided, but there aren't any. There is some repetition of points in individual chapters. It is a great pity that the authors of an excellent collection of essays have been let down somewhat by their publisher. Nonetheless, the book is recommended for academics, students, lawyers and judges.

Charles Oppenheim 